\title{
Variaciones en torno a la "interamericanización" del derecho. A propósito del Ius Constitutionale Commune ${ }^{1}$
}

\section{Leonardo García Jaramillo \\ Universidad EAFIT-Medellín (Colombia)}

La "confusión entre lo global y lo local" es uno de los enfoques desde los cuales Held analiza la globalización ${ }^{2}$. Este enfoque se observa sobre todo en el derecho debido a la erosión contemporánea de las fronteras entre el derecho local y el derecho extranjero. Aunque los países latinoamericanos han tenido tradicionalmente autoridades permisivas en sus fronteras que han permitido e incluso fomentado el tránsito de bienes, servicios, capital, personas, cultura, tecnología y conocimiento, en la actualidad este intercambio se ha intensificado y ha empezado a cuestionar las formas hegemónicas de creación del constitucionalismo latinoamericano.

Los patrones particulares de desarrollo que la globalización del derecho ha creado para el derecho constitucional se explican a partir de las afinidades orgánicas (creación de tribunales independientes y mecanismos de garantía a los derechos y participación) y dogmáticas (principios y derechos consagrados de forma similar como disposiciones constitucionales) que caracterizan los procesos de reforma constitucional en la región durante los últimos 25 años.

En esta complejización del fenómeno constitucional latinoamericano, por el mayor número de variables que entran en juego en su creación y desarrollo, adquieren particular relevancia el derecho extranjero y los instrumentos del Sistema Interamericano de Derechos Humanos. Experiencias locales relativas a la implementación de normas o doctrinas también viajan para no repetir hechos desafortunados del pasado y para aprender de la experiencia regional en la solución de nuestros problemas más acuciantes.

En contextos afines signados, de un lado, por la pobreza, la desigualdad y los déficit en la representación política, y de otro, por la proclamación de constituciones con vocación normativa, un amplio catálogo de derechos, mecanismos judiciales para propender por su garantía y un tribunal independiente encargado de proteger y desarrollar estas provisiones, se

\footnotetext{
${ }^{1}$ Armin von Bogdandy, Héctor Fix Fierro y Mariela Morales (coords.): Ius Constitutionale Commune en América Latina: rasgos, potencialidades y desafios. México D.F.: UNAM-IIJ - Instituto Max Planck de Derecho Público, Comparado y Derecho Internacional, 2014. 525 pp.

${ }^{2}$ David Held - Anthony G. Mcgrew, et al., Global Transformations: Politics, Economics, and Culture. Stanford, Stanford University Press, 1999.
} 
comprende porqué la academia jurídica y los tribunales nacionales, así como la Corte Interamericana, han llegado a compartir intereses teóricos, métodos analíticos y doctrinas sustantivas que propician el desarrollo y la consolidación de un derecho constitucional genérico latinoamericano al cual, siguiendo teorizaciones sugestivas como la propuesta por Morales Antoniazzi, podríamos denominar "interamericanización".

La globalización del derecho en América Latina, hasta hace relativamente poco tiempo, dejó de estar determinada por países del primer mundo exportadores de derecho, hacia países del tercer mundo: importadores con escasa o nula autoridad retributiva en esta relación de poder y dependencia. Para comprender las particularidades de este cambio adquiere relevancia el concepto “interamericanización". La soberanía y las fronteras siguen fracturadas pero ya no solo para dejar entrar flujos sino también para exteriorizarlos. Estándares normativos se crean y desarrollan a partir del diálogo y la interacción. Como sucede con la globalización comercial, el consumidor local ha tendido a atribuir mayores niveles de calidad y prestigio a los productos extranjeros: carros, relojes y computadores, así como legislación, instituciones políticas y ciencia jurídica. Para los países del sur global los atributos que ofrece la comparación (apropiación, préstamo, trasplante...) han sido fuente de inspiración y de legitimación. ${ }^{3}$ Uno de los desafíos de la interamericanización del derecho es dotar de mayor autoridad y legitimidad a los productos jurídicos que siembra y cosecha. El derecho constitucional reconocible hoy en América Latina está construyendo su legitimidad y autoridad en la dimensión regional donde acontecen hoy intensos flujos e intercambios.

Uno de los grupos de especialistas más reconocidos en la actualidad, procedentes de distintos países europeos y latinoamericanos, que se han conformado desde hace poco más de una década para estudiar el nuevo constitucionalismo latinoamericano se coordina desde el Instituto Max Planck de Derecho Público Comparado y Derecho Internacional, en HeidelbergAlemania. Liderados por Armin von Bogdandy y Mariela Morales Antoniazzi, han desarrollado un proyecto que adquiere cada vez mayor relevancia en la región. El proyecto se sustenta en la convicción por el poder de transformación social del constitucionalismo, en la confianza compartida por el rol que el derecho tiene que desempeñar en cambios de gran magnitud requeridos con urgencia.

"Ius Constitutionale Commune en América Latina" (ICCAL) es un concepto útil para para comprender este complejo fenómeno de la interamericanización académica y judicial del derecho. Procura igualmente proyectar rumbos de acción hacia un constitucionalismo transformador de las desigualdades sociales

${ }^{3}$ Michel Rosenfeld - András Sajó (eds.), The Oxford Handbook of Comparative Constitutional Law. Oxford University Press, 2012, "Introduction".

Araucaria. Revista Iberoamericana de Filosofia, Política y Humanidades, año 18, no 36. Segundo semestre de 2016. Pp. 511-521. ISSN 1575-6823 e-ISSN 2340-2199 doi: 10.12795/araucaria.2016.i36.23 
y políticas que aquejan a los países de la región. Tiene por tanto aspiraciones descriptivas y prescriptivas. El ICCAL contribuye a estructurar un diálogo académico, político y judicial que puede rendir efectos en los procesos de aplicación del derecho. El proyecto que desarrolla el concepto tiene horizontes teórico-analíticos, normativos y comparados.

El ICCAL: un concepto incluyente con una agenda liberal y progresista aunque no partidista, se centra en las nuevas formas de comprender, analizar y proyectar debidamente los elementos medulares del derecho público en el contexto de los procesos de globalización económica y jurídica del mundo occidental, a partir de un abordaje sistémico entre los órdenes normativos nacional y regional en lo relativo a la protección de los derechos humanos. Los hechos que fundamentan el concepto, son: El hecho social de pobreza y desigualdad en la región ${ }^{4}$ y el hecho político en virtud del cual los órganos representativos han mostrado desidia, incapacidad o inacción para acometer reformas sociales urgentes, lo cual a nivel inmediato se refleja en una deficiencia de políticas públicas estructurales y un desencanto frente a la política. Esto último ha derivado en una baja participación política que se manifiesta en abstención electoral y falta de interés por la res publica. Un tercer hecho sería el institucional que refleja la esperanza social fincada en los tribunales constitucionales para remediar problemas sociales y políticos. La conjunción de estos tres hechos, en países con constituciones normativas y derechos vinculantes, ha derivado en un inédito protagonismo judicial y en un empoderamiento político del juez.

\section{Objetivos, conceptos medulares y características del ICCAL}

El potencial emancipador del derecho en contextos de graves violaciones a los derechos humanos y constituciones progresistas, articula otro objetivo central: el desarrollo del Estado abierto o la estatalidad abierta (offene Staatlichkeit). Acuñado por Klaus Vogel, hace referencia a la apertura del derecho nacional al derecho internacional. En virtud del Estado abierto, el sistema jurídico dispone de canales para el influjo del derecho internacional público como fuente a partir de las cláusulas de apertura o reenvío, que son las disposiciones constitucionales que permiten interpretar armónicamente una norma o un conjunto de normas constitucionales con otros textos (un texto normativo concreto, un conjunto de textos normativos, un principio derivado

\footnotetext{
4 Por caso, en Colombia en 2014 la pobreza monetaria (ingresos que no alcanzan para la canasta básica) se registró en 28,5\%. La desigualdad es de 0,538 evaluada con el coeficiente de Gini (0 absoluta igualdad y 1 inequidad absoluta). Tiene la tercera peor desigualdad entre 129 países de las Naciones Unidas. Solo supera a Haití y Angola. La realidad de la región no dista de este fenómeno como señala Piovesán.
} 
de la jurisprudencia interpretativa como la igualdad o la dignidad humana, o un conjunto de principios como los del derecho internacional). Mariela Morales examina el alcance del Estado abierto como objetivo central del ICCAL, en particular, respecto del impacto que en su configuración y garantía tienen las sentencias de la Corte Interamericana.

El desarrollo del Estado abierto conduce necesariamente a reconcebir un concepto central en la teoría del Estado. La soberanía nacional no explica ya por sí sola las influencias y las relaciones a partir de las cuales se crea y desarrolla el derecho nacional. Se ha transformado para acoger estándares más elevados respecto del cumplimiento de principios fundamentales como los consagrados en el Sistema Interamericano de Derechos Humanos (Piovesan). En 1915 el derecho internacional se mostró incapaz de detener el genocidio turco en Armenia. Los crímenes del nazismo obligaron a repensar y a cuestionar el dogma del Estado soberano y el principio de no interferencia en las cuestiones nacionales. Al término de la Segunda Guerra se tornó imperativo cuestionar las violaciones atroces a los derechos humanos en vez de omitirlas por considerarlas un asunto nacional ${ }^{5}$.

El ICCAL aborda el impacto del Sistema Interamericano de Derechos Humanos en la configuración de un derecho constitucional común, destacando las transformaciones que ha promovido. Las ideas de Estado y soberanía se han permeabilizado para permitir filtrar al derecho interno estándares normativos provenientes de la jurisprudencia interamericana, de los comités y sentencias de otros tribunales. La progresiva efectividad del diálogo jurisdiccional ha derivado en un empoderamiento del Sistema Interamericano y en una creciente legitimación social de su rol democratizador en la región (Piovesán y García Ramírez coinciden en este punto).

Sobre todo en materia de derechos humanos las fronteras no son ya las de los estados sino las del conocimiento común compartido acerca de una idea de dignidad humana que ha evolucionado del ideario político a la dogmática jurídica para fundamentar el discurso de protección y promoción a los derechos humanos. Ya no es la soberanía la que condiciona la garantía de los derechos, sino que los derechos condicionan normas jurídicas y prácticas administrativas, otrora soberanas, porque están ahora sometidas a un control adicional respecto de los tradicionales controles de legalidad y constitucionalidad, como es el control de convencionalidad. Este control, como enfatiza Mariela Morales, contribuye a configurar y expandir el derecho constitucional común en América Latina. Sobre el control de convencionalidad frente a la autoridad de la cosa juzgada internacional, resulta de particular interés la inclusión en el libro del voto de Ferrer Mac-Gregor a la Resolución

${ }_{5}$ M. Nowak, Introducción al régimen internacional de los derechos humanos. Universidad de Buenos Aires, Facultad de Derecho, 2009.

Araucaria. Revista Iberoamericana de Filosofía, Política y Humanidades, año 18, n 36 . Segundo semestre de 2016. Pp. 511-521. ISSN 1575-6823 e-ISSN 2340-2199 doi: 10.12795/araucaria.2016.i36.23 
de la Corte sobre la supervisión de cumplimiento de sentencia en el Caso Gelman.

La idea del Estado abierto conduce a defender la comparación jurídica como herramienta para la construcción de la doctrina y la dogmática jurídicas. La importancia de la perspectiva comparada radica en que conocer mejor otros sistemas y otras formas de hacer las cosas, a nivel de la implementación de la normativa constitucional, incrementa el conocimiento compartido en la región frente a desafíos comunes como la garantía de los derechos humanos, el robustecimiento de la democracia y la consolidación del estado de derecho, los cuales así mismo constituyen los objetivos fundamentales del ICCAL. Las tensiones institucionales que se presentan entre el neoliberalismo y el populismo exigen un enfoque que articule a los derechos humanos, la democracia y el estado de derecho.

Una vez se sustentan las ideas del Estado abierto, la reconfiguración del principio de soberanía nacional y la comparación jurídica, adquiere fuerza la idea del diálogo. Entre las formas que puede tomar, el ICCAL prioriza el diálogo entre tribunales. Sin adolecer de una perspectiva judicialista, debido a su enfoque en los derechos y en sus mecanismos de protección, el ICCAL le atribuye una gran relevancia al rol institucional de los jueces y las cortes en los procesos de transformación social desde el constitucionalismo. La perspectiva dialógica se ha incorporado con fuerza al debate constitucional para cuestionar y criticar el juris-centrismo en la configuración del derecho constitucional, es decir, la perspectiva excesivamente centrada en el poder judicial como único actor en el proceso de interpretar y desarrollar del derecho $^{6}$. El juris-centrismo comporta una esperanza desmedida en las capacidades judiciales para transformar a la sociedad ${ }^{7}$.

La forma para conseguir que los tribunales sean democráticos no es repitiendo experiencias desafortunadas como la boliviana donde se vota en elecciones públicas por la elección de magistrados. Los tribunales no deben tratar de convertirse en instituciones democráticas como los parlamentos. Deben articularse con mecanismos que democraticen, legitimen y así reflejen alguna representación ${ }^{8}$. El diseño de mecanismos que reduzcan la tensión entre la justicia constitucional y la democracia, es la forma de superar el costo que

${ }^{6}$ Entre otros, véase: R. Post - R. Siegel, Constitucionalismo democrático. (Leonardo García J., ed. acad. y trad.). Buenos Aires: Siglo XXI, 2013. R. Gargarella (comp.), Por una justicia dialógica. Buenos Aires: Siglo XXI, 2014.

7 Para una perspectiva proactiva de la función judicial en el marco de las políticas públicas, pero consciente de sus capacidades y restricciones institucionales, véase, J. C. Henao, "El juez constitucional: un actor de las políticas públicas", Revista de Economía Institucional 15, 29, 2013.

${ }^{8}$ Fundamentalmente: Representación simbólica -identificación emocional entre el representante y el representado- o sustantiva - enfatiza la necesidad de analizar el contenido sustantivo de la actividad de representar, que aparece definida como actuar en beneficio de otro o teniendo en cuenta sus intereses-. Véase, Hanna Pitkin, The Concept of Representation. The Concept of Representation. University California Press, 1967. 
supone el control constitucional y es uno de los importantes desafíos hacia los que se dirige el ICCAL 9 .

La idea del diálogo judicial requiere elaboración conceptual y verificación práctica de los mecanismos ya implementados para realizarla, tales como la solicitud y consideración de amicus curiae por parte de especialistas, las audiencias públicas donde, antes del fallo, la academia y miembros del gobierno, de partidos políticos y de la sociedad civil organizada en ONG, por ejemplo, presentan sus perspectivas constitucionales sobre el asunto en cuestión; o audiencias posteriores al fallo donde se rinden cuentas sobre las órdenes impartidas en la sentencia. El fortalecimiento de estos mecanismos y el planteamiento de otros nuevos constituyen desafíos importantes para el ICCAL, toda vez que rebaten cuestionamientos hacia el control judicial de constitucionalidad pero, sobre todo, hacia un poder judicial proactivo y activista.

\section{Restricciones institucionales al activismo judicial: los derechos como fenomenos complejos}

Formas que se han ensayado en la región para transformar a las sociedades y hacerlas más igualitarias y equitativas, social y políticamente, han derivado en populismos y presidencialismos exacerbados, como en el caso -con diferencias de grado- de Venezuela, Nicaragua, Ecuador y Bolivia. El ICCAL propugna en cambio por un empoderamiento del poder judicial, sustentado en la preeminencia que la fuerza vinculante de los derechos y la naturaleza normativa de la constitución han adquirido en el lenguaje jurídico y en la configuración de la acción política.

La institucionalidad, reflejada en la independencia judicial real, en un sistema de frenos y contrapesos operativo, y en el respeto a las libertades y los derechos políticos, se considera un presupuesto para garantizar los derechos humanos, robustecer la democracia y consolidar el estado de derecho. Bogdandy, Salazar Ugarte, Morales y Arango abordan este punto. En una democracia constitucional se privilegia la soberanía popular representada en una constitución respecto de las decisiones políticas provenientes de los poderes legislativo y ejecutivo. Este libro muestra cómo cortes activistas en América Latina han encontrado formas de conducir y alcanzar procesos de

\footnotetext{
${ }^{9}$ El control judicial interfiere de hecho con la legitimidad democrática del parlamento, pero la cuestión es determinar el grado de tal interferencia respecto de la importancia de satisfacer el principio de protección de los derechos fundamentales que exige lograr su mayor realización posible. Véase, R. Alexy, "Revisión judicial de constitucionalidad como representación argumentativa" (Leonardo García J., trad.), en: J. C. Henao (ed.) Diálogos constitucionales con el mundo. Bogotá, Universidad Externado - Corte Constitucional, 2013.
} 
democratización, y así han sido actores institucionales fundamentales que han traído con su jurisprudencia procesos de democratización.

En este sentido, Piovesan presenta una interesante tipología de casos sobre la base de las decisiones relativas a cinco diferentes categorías de violación de los derechos humanos: 1. Violaciones que reflejan el legado del régimen autoritario dictatorial (Velásquez Rodríguez vs. Honduras), 2. Violaciones que reflejan cuestiones de la justicia de transición (Caso Barrios Altos Vs. Perú), Violaciones que reflejan desafíos acerca del fortalecimiento de las instituciones y de la consolidación del Estado de derecho (Tribunal Constitucional vs. Perú), 4. Violaciones de los derechos de grupos vulnerables (Comunidad Indígena Mayagna Awas Tingni vs. Nicaragua) y 5. Violaciones a los derechos sociales (Villagrán Morales vs. Guatemala).

El poder judicial no obstante no está en capacidad de soportar enteramente el proyecto de un constitucionalismo transformador. La importancia del nuevo rol del juez en la implantación y consolidación de los principios constitucionales reivindicados por el ICCAL, no debería conducir, a mi juicio, a sostener, como hace Fix-Fierro, que "en las manos del juez está el futuro del derecho constitucional común latinoamericano". La perspectiva juris-céntrica de la interpretación y configuración del derecho constitucional, debe ceder ante una más conectada con la política y con los movimientos sociales.

Salazar Ugarte sustenta que los jueces por sí solos no pueden ofrecer garantías plenas a los derechos y que los derechos no pueden demandar únicamente una protección jurisdiccional. Sin desestimar la función judicial, enfatiza que la justiciabilidad de los derechos, como fenómenos complejos, requiere de garantías políticas, económicas e incluso sociales, así como de un contexto cultural que los sustente.

Una adecuada concepción de los derechos como fenómenos complejos es central para resolver la tensión entre el constitucionalismo (los principios y valores) y la democracia (el principio de autogobierno colectivo y la regla de mayorías); entre lo que pueden hacer las mayorias directamente o por intermedio de sus representantes, y la concepción de las normas de derecho iusfundamental como límites a la voluntad política mayoritaria. La debida delimitación de los espacios de acción institucional entre los jueces y el legislador, es una condición necesaria para hacer realidad el respeto y la vigencia de los derechos fundamentales.

El derecho constitucional en sede judicial debe pasar del activismo judicialmente ensimismado, a uno más en sintonía con las perspectivas constitucionales de otros actores. La legitimidad democrática del constitucionalismo radica en que las sentencias surjan no sólo de estrictos razonamientos judiciales, sino también de interacciones entre el poder judicial y otras ramas del poder público, asociaciones civiles, partidos políticos, think tanks, movimientos sociales, centros de investigación, ONG y el poder judicial 
en conjunto. En contextos de constitucionalización del derecho, desarrollo de la normativa material de la constitución y judicialización de la política, el poder judicial debe moderar su activismo progresista y ser sensible, o receptivo, hacia la sociedad civil organizada.

\section{Inclusión, igualdad real y derechos sociales}

El ICCAL incorpora la inclusión en los sistemas social, económico y político como uno de sus elementos medulares. La inclusión plantea desafíos a la transformación social mediante el constitucionalismo, sobre todo, respecto de la garantía a los derechos sociales como precondiciones para el ejercicio de los derechos de libertad población en situación de déficit en la protección de sus derechos. Su garantía crea las condiciones materiales necesarias para lograr una mínima igualdad, que es esencial para el ejercicio efectivo de la libertad. La función de las autoridades públicas respecto del goce efectivo de los derechos, no solo consiste en garantizar esferas libres de interferencia ajena a los ciudadanos, protegiendo su derecho a la libertad de expresión, consciencia y locomoción, por ejemplo, sino también en asegurar condiciones materiales mínimas de existencia, de lo cual emana la realización estatal progresiva de los derechos sociales ${ }^{10}$.

La persona desfavorecida valora que haya derechos que le protejan de la esclavitud o que le garanticen las libertades de expresión, culto y circulación, pero para esa misma persona tendrán más importancia los derechos que le permitan superar su situación existencial deficitaria. La importancia de proteger los derechos sociales radica en que procuran crear las condiciones materiales necesarias para lograr una mínima igualdad, que es esencial para el ejercicio efectivo de la libertad, es decir, son un presupuesto para el ejercicio de los derechos de libertad para la población en situación de déficit en la protección de sus derechos.

La lucha contra la desigualdad es esencial para alcanzar una verdadera autonomía. Arango sostendrá que los tres principios fundamentales que configuran el marco donde se libra esta lucha son: los derechos fundamentales, la democracia y la justicia constitucional. En la región se ha acogido ampliamente la tesis de la concepción integral de los derechos fundamentales, en virtud de la cual todos, sean de libertad o sociales, pueden adquirir estatus iusfundamental. Defiende una concepción social de la democracia, por sobre otras como la deliberativa (que a su juicio es demasiado ideal para ser sensible a sectores sociales tradicionalmente discriminados). La adopción de la fórmula política del Estado social y democrático de derecho exige al Estado intervenir

\footnotetext{
${ }^{10}$ Corte Constitucional Colombiana, sentencia C-251 de 1997.
} 
en la economía y en el proceso político para asegurar los fines sociales esenciales. La garantía para la realización de los derechos y la democracia, es la jurisdicción constitucional, cuya función es resguardar la primacía de las normas constitucionales sobre las demás normas de los ordenamientos jurídicos nacionales.

Laura Clérico y Martín Aldao, en su contribución sobre diversos problemas teóricos y prácticos de la igualdad, proponen una concepción de la igualdad como redistribución/reconocimiento para lograr paridad participativa. Revisan críticamente las fórmulas tradicionales de la igualdad para reinterpretar el desafío de la inclusión en el contexto del derecho constitucional interamericano. Esta idea de inclusión no puede omitir la fórmula de la igualdad, así como las concepciones y el alcance de la exigencia de igualdad aplicada. La inclusión debe concebirse desde la igualdad entendida desde una perspectiva amplia como no dominación. La propuesta se evalúa a partir de casos de la Corte Interamericana sobre comunidades indígenas. Un enfoque sobre el constitucionalismo transformador no puede omitir el tema del derecho económico y en particular en su dimensión internacional. Si bien la igualdad y la redistribución son temas contenciosos, hay un consenso asentado en cuanto a que la exclusión y la pobreza deben superarse no solo por razones morales sino políticas toda vez que generan perversidades en los sistemas democráticos. Grandes grupos sociales no solo no participan de los beneficios del progreso sino que no hacen parte de los sistemas de salud, electorales y educativos.

El Sistema Interamericano de Derechos Humanos se estableció entre 1948 y 1978 cuando la democracia en América Latina era inestable, había una mayor pobreza y se presentaban violaciones masivas a los derechos humanos. Si bien, como señala Malamud, en la actualidad la región exhibe progresos en esas tres áreas, se atraviesa por malos momentos. Las clases políticas tradicionales y las emergentes (Colombia, Brasil, Nicaragua, Venezuela, Bolivia), gozan de muy poca credibilidad y con creciente desconfianza. Los déficits en la representación real del grueso de la población ante las instancias de toma de decisiones políticas, facilitan la aprobación de medidas parcializadas. Además de la exclusión, la desigualdad social y la falta de representación política, se presenta una desconfianza frente a las instituciones e incluso frente a la democracia como sistema de gobierno ${ }^{11}$.

Si bien durante las últimas décadas se ha avanzado en el cumplimiento de criterios básicos propios de regímenes político-democráticos, los progresos alcanzados en la democracia electoral no han contribuido con el desarrollo de una democracia real. Es más, el ejercicio de la democracia electoral en muchos

${ }^{11}$ Como señala Piovesán: En el Latinobarómetro 2011 frente a la pregunta “¿La democracia es preferible a cualquier otra forma de gobierno?", la respuesta afirmativa tuvo en Brasil una aprobación del 45\%, en México del 40\% y en Guatemala del 36\%. 
contextos signados por la pobreza y la desigualdad, ha contribuido a agravar déficits democráticos. La razón es que ciudadanía en situación de necesidad es fácilmente manipulable electoralmente, por lo que funcionarios públicos que aspiran reelegirse o nuevos candidatos, si bien montan una plataforma política y se identifican más o menos con determinada ideología, saben que sobre todo necesitan ingentes recursos para realizar una campaña exitosa. Con recursos se consiguen victorias, pero se generan profundos problemas de representación política, pues el elegido no se siente comprometido con quienes lo eligieron sino con quienes financiaron su campaña. Dentro de esta lógica perversa se agravan, a su vez, otras falencias de las democracias latinoamericanas: la corrupción y el clientelismo.

Estas realidades plantean enormes desafíos pero demuestran la relevancia de contar con un sistema interamericano dialógico (Piovesan, Morales) que contribuya a que los países cumplan con estándares normativos reconocidos por la Convención. La relevancia académica e institucional del Ius Constitutionale Commune se hace cada vez más notoria en tanto avanzan en los países de la región las controversias por el alcance de la normativa interamericana. Hay estados que son (parafraseando a algún analista que sostuvo algo similar respecto de Venezuela) "anatómicamente democráticos pero fisionómicamente anti-democráticos", es decir, Estados que en apariencia son respetuosos de los derechos y de las instituciones democráticas, pero en su funcionamiento real no hay una adecuada representación política, no hay estatuto que proteja a la oposición, y se asesinan disidentes y periodistas, por ejemplo.

En la actualidad la falta de garantía - o violación- a los derechos, liberales y sociales, constituye el principal riesgo que enfrentan las democracias. Salazar Ugarte, desarrollando una idea presente en Bobbio según la cual la democracia, los derechos y la paz son tres etapas de un mismo movimiento histórico, sustenta que la democracia necesita de los derechos para consolidarse como una forma de gobierno sustentada por la autonomía política de las personas.

\section{Academias (y no solo tribunales) activistas}

La influencia que la academia pueda llegar a ejercer en las maneras prevalentes de interpretar y configurar el derecho constitucional, y de amparar el goce efectivo de derechos sociales, exige una postura más proactiva respecto del usual trabajo de la academia. "No hay revolución sin teoría revolucionaria", como indica Bogdandy en su contribución que dice un mural en la Facultad de Derecho de la UNAM, lo cual no invita a la revolución sino que refleja aquella idea expresada por Hegel: "si se revoluciona el reino de la representación, la realidad no puede aguantar". 
Una tarea fundamental de la academia jurídica latinoamericana es la depuración y sofisticación conceptual que conduzcan a mejores prácticas, para posteriormente sistematizar los nuevos materiales jurídicos que surjan. Las herramientas para transformar a la sociedad las tienen los sistemas constitucionales, los cuales dependen de construcciones teóricas que, a su vez, son dependientes de conceptos. Plantear y precisar conceptos depende de una academia sólida, intercomunicada y activa que contribuya a desarrollar el derecho hacia los fines que establecen los estados constitucionales.

En este contexto es inconveniente que la academia tenga una deferencia acrítica hacia el poder judicial, pues le corresponde uno de los controles más importantes en las nuevas democracias constitucionales, como es el control a la labor del tribunal constitucional. Toda vez que este control es extra jurídico, porque está por fuera de las instituciones formales, el rol de la academia es esencial para controlar y vigilar la actividad de los tribunales constitucionales. Un cambio de enfoque y un mayor compromiso crítico y propositivo es fundamental para contribuir a dar respuesta a la objeción de ¿Quién controla al controlador?, ¿Quién nos defiende del defensor de la constitución? En este sentido, a medida que se incrementa la demanda por un tipo especial de juez, más poderoso, debe aumentarse también la exigencia por una academia crítica.

La academia comprometida con el logro de los objetivos del ICCAL tiene también un papel fundamental que desempeñar en la crítica a la jurisprudencia, en la veeduría a los organismos del poder público encargados de garantizar los derechos y en la difusión ciudadana de las mejores ideas y posiciones jurídicas ante casos controversiales, mediante, por ejemplo, columnas de prensa, participación en programas de radio y televisión, y con una activa participación en la configuración de una opinión pública deliberante y crítica. A los académicos progresistas comprometidos con el constitucionalismo transformador, corresponde cuestionarse por formas efectivas de influenciar el diálogo constitucional. El ICCAL puede orientar en la tarea de contribuir a desarrollar una perspectiva política para la sociedad civil que sea capaz de generar amplios apoyos populares.

Bryan Magee ironiza a los filósofos analíticos obsesionados con examinar el significado de las palabras y las formas como se utilizan, asemejándolos a una persona que pasa todo el tiempo limpiando sus lentes pero nunca se los coloca para poder ver mejor al mundo ${ }^{12}$. De igual forma se podría ironizar a los constitucionalistas encumbrados en la reflexión y la meditación, mientras las sociedades se desarraigan y los déficits en la garantía a los derechos continúan y se acrecientan. La preocupación del ICCAL no es exclusivamente teórica o analítica, consistente en la depuración de conceptos jurídicos y la defensa del contenido preciso de determinadas concepciones políticas. Trabaja en torno a la certeza acerca de la capacidad del derecho para transformar la sociedad.

${ }^{12}$ B. Magee, Confessions of a Philosopher. A Personal Journey through Western Philosophy from Plato to Popper. New York, Random House, 1998.

Araucaria. Revista Iberoamericana de Filosofía, Política y Humanidades, año 18, n 36. Segundo semestre de 2016 Pp. 511-521. ISSN 1575-6823 e-ISSN 2340-2199 doi: 10.12795/araucaria.2016.i36.23 
